\title{
Ensino de Língua Portuguesa e o Gênero Redação: Uma Análise do Discurso do Professor
}

Francisca Ilani Alves Maial, Henrique Miguel de Lima Silva², Sayonara Abrantes de Oliveira Uchoa ${ }^{3}$, Symara Abrantes Albuquerque de Oliveira Cabral ${ }^{4}$, Maria Carmem Batista de Alencar ${ }^{5}$, Stephanny Batista de Alencar Roberto ${ }^{6}$, Jalder Alison da Silva Maciel $^{7}$

Resumo: Trata-se de pesquisa sobre como o professor trabalha o ensino de língua portuguesa em sala de aula, utilizando o gênero redação nas séries do ensino médio. Pressupõe-se que uma das maiores dificuldades da produção textual do gênero redação seja decorrente de um ensino metalinguístico e que desconsidere a finalidade da língua enquanto prática de interação social. Considerando a importância da língua no processo de interação social e a necessidade de mudanças significativas na prática pedagógica, surge a oportunidade de trabalhar-se com os gêneros textuais, tendo em vista que os mesmos fazem parte das necessidades do aluno a todo momento. Sendo assim, foi desenvolvido um estudo de caso, sobre o ensino dos gêneros textuais, com foco na redação e a partir de questionários aplicados analisou-se o discurso do professor de língua portuguesa e as suas práticas de ensino, fechando a última parte do artigo.

Palavras-Chave: Gêneros Textuais. Ensino. Professor.

\section{Portuguese Language Teaching and Writing Gender: A Teacher's Discourse Analysis}

Summary: This is a research on how the teacher works the Portuguese language teaching in the classroom, using the genre writing in high school grades. It is assumed that one of the biggest difficulties of textual production of genre writing is due to a metalinguistic teaching and disregard the purpose of the language as a practice of social interaction. Considering the importance of language in the process of social interaction and the need for significant changes in teaching practice, there is the opportunity to work with the genres, with a view that they are part of the student's needs at all times. Thus, we developed a case study on the teaching of genres, focusing on writing and from questionnaires analyzed the teacher's speech of the Portuguese language and its teaching practices, closing the last part of the article .

Keywords: Text Genre. Teaching. Teacher.

\footnotetext{
${ }^{1}$ Graduação em Letras - Universidade Estadual da Paraíba.

${ }^{2}$ Doutorando em Linguística - Universidade Federal da Paraíba - João Pessoa - PB, Brasil. E-mail: henrique.miguel.93@hotmail.com.

${ }^{3}$ Doutoranda em Linguística - Universidade Federal da Paraíba - João Pessoa - PB, Brasil. E-mail: sayonara_abrantes@ hotmail.com.

${ }^{4}$ Doutoranda em Ciências da Saúde - Faculdade de Ciências Médicas da Santa Casa de São Paulo, Brasil.

E-mail: symara_abrantes@ hotmail.com;

${ }^{5}$ Mestranda em Sistemas Agroindustriais - Universidade Federal de Campina Grande. Paraíba E-mail: carmemsjp@ hotmail.com;

${ }^{6}$ Graduada em Enfermagem - Faculdade Santa Maria. Cajazeiras, Paraíba, Brasil. E-mail: stephanny_cg@ hotmail.com;

${ }^{7}$ Graduado em Farmácia - Faculdade Santa Maria. Cajazeiras, Paraíba, Brasil. E-mail: jalderalison@hotmail.com.
} 
Id on Line Revista Multidisciplinar e de Psicoloqia

Id on Line Multidisciplinary and Psychology Journal

\section{Introdução}

O ensino de língua portuguesa, mais especificamente, no Brasil, vem, há bastante tempo, sofrendo inúmeras reflexões que, por sua vez, são decorrentes, da concepção de língua adotada nas escolas como um todo. Sabe-se ainda que tais concepções são decorrentes das teorias linguísticas desenvolvidas ao longo do século XX, bem como no século XXI.

Em um primeiro momento, a concepção de língua enquanto estrutura segundo Saussure (1916) implicava diretamente no ensino de língua portuguesa ao conceber que o domínio das estruturas linguísticas deixaria o sujeito proficiente na língua em questão.

Aliado a este paradigma estrutural, Chomsky (1965), ao trabalhar com uma teoria linguística voltada para à competência linguística, afirma que o sujeito já nasce com o sistema da língua na mente/cérebro e que as motivações sociais ativam o conhecimento linguístico.

Dessa teoria gerativa, tem-se como desdobramento a noção de competências linguísticas e que, no campo do ensino de língua materna, nesta concepção, competiria ao professor tornar o sujeito proficiente a partir do domínio das estruturas.

Percebe-se que em ambos os autores prevalece que ser proficiente é ter domínio da estrutura linguística. Fato que, conforme Fiorin (2009) foi predominante no ensino de língua portuguesa no Brasil e que, mesmo com o surgimento dos documentos prescritivos que, por sua vez, passaram a nortear o ensino de língua de uma maneira diferenciada, pouco mudou-se na prática. (BRASIL, 1998)

Uma terceira concepção, fortemente influenciada por estudos anteriores à sua propagação, com estudos de Jakobson (CAMARA, 2009), Bakhtin (1929), dentre outros; concebiam à língua enquanto uma realidade sociohistória e situada; ou seja, decorrente de práticas sociais e que, por sua vez, só tinham sentido considerando-se o sujeito, a cultura, o outro e a história enquanto componentes do sistema linguístico.

Esta mudança paradigmática nos estudos da linguagem proporcionou profundas reflexões sobre o ensino de língua que, por conseguinte, correlacionados com o momento histórico de final de ditadura no Brasil (BRASIL, 1988), resultou na criação de novos documentos para educação, bem como para inclusão do artigo V que afirma que a "educação é dever do estado". 
Id on Line Revista Multidisciplinar e de Psicologia

Id on Line Multidisciplinary and Psychology Journal

É justamente dentro desse paradigma científico de mudanças nas concepções de língua e, dessa maneira, do ensino, entra em cena o ensino de língua portuguesa baseado na perspectiva dos gêneros textuais (BRASIL, 1998).

Ainda em se tratando da temática abordada, os documentos oficiais do ensino de língua portuguesa partem do princípio de um ensino que surja dos conhecimentos prévios dos estudantes e, em seguida, trabalhe com gêneros mais complexos que, por sua vez, circulam em esferas sociais específicas. (BRASIL, 1998).

Sabe-se que desenvolver as habilidades e competências linguísticas dos alunos tem sido uma prática desafiadora para muitos professores, tendo em vista a necessidade da melhoria da educação brasileira. Logo, refletir sobre as contribuições do ensino, mais especificamente, de língua portuguesa para o sujeito construtor do saber nos permite enxergar um compromisso do sistema educacional para a transformação do cenário social do país.

Dentro do universo de conhecimentos linguísticos ensinados na sala de aula, selecionou-se o gênero redação por ser um dos mais exigidos pelos alunos concluintes da educação básica, bem como uma das portas de entrada para o ensino superior, uma vez que essa produção textual vale metade da nota no Exame Nacional do Ensino Médio, dependendo da instituição.

Pressupõe-se que uma das maiores dificuldades da produção textual do gênero redação esteja decorrente de um ensino metalinguístico e que desconsidere a finalidade da língua enquanto prática de interação social; tendo o ensino predominantemente voltado para o domínio das estruturas linguísticas.

Diante disso, surge o interesse de analisar como o professor trabalha o ensino de língua portuguesa em sala de aula, utilizando o gênero redação nas séries do ensino médio. De acordo com os PCN'S (BRASIL, 1998), todo aluno deve ser capacitado para compreender e exercer a cidadania, posicionando-se de maneira crítica nas mais variadas situações sociais, deve perceber-se como agente transformador, contribuindo de forma significativa na sociedade, deve ainda, desenvolver as capacidades cognitivas, éticas, afetivas, utilizando a linguagem para produzir e expressar ideias, questionando a realidade e utilizando sua capacidade de análise crítica.

Ao trabalhar com o gênero textual redação nas aulas de língua portuguesa, o professor torna o ensino da mesma uma prática significativa de aprendizagem, desenvolvendo a 
Id on Line Revista Multidisciplinar e de Psicoloqia

Id on Line Multidisciplinary and Psychology Journal

competência linguística dos alunos, Marcushi, 2008. Nesse sentido, pretende-se com essa pesquisa, analisar o conhecimento que o professor de língua portuguesa possui a partir do seu discurso, como também, verificar se o professor conhece as prescrições sobre o ensino de gênero que possibilita refletir sobre o ensino de língua portuguesa a partir do gênero redação.

Tem-se como justificativa, investigar a prática pedagógica do professor no que se refere à utilização do gênero textual redação, para refletir sobre o ensino de língua portuguesa com base nos PCN'S. Para conduzir a investigação e análise deste trabalho foi realizado um estudo de caso e a utilização de questionário.

Elaboramos um questionário constituído de 06 (seis) perguntas e entregamos à 04 (quatro) professores do ensino médio que lecionam em escolas particulares na cidade de Catolé do Rocha para que os mesmos respondessem as perguntas e em seguida fizemos o recolhimento para analisar as respectivas respostas. A maioria dos professores investigados estão em sala de aula há mais de 10 (dez) anos, dentre eles, somente o professor 3 possui mestrado, o restante possui somente graduação.

O presente trabalho foi divido da seguinte forma: primeiro ponto trata sobre algumas considerações dos gêneros textuais, em seguida, discorremos mais especificamente sobre o gênero redação, na sequência têm-se o discurso do professor à luz da teoria Bakhtiniana juntamente com a análise do questionário, fechando a última parte do artigo. Baseando-se nos pressupostos teóricos de Brasil (1998), Bakhtin (2000), Antunes (2002), Bazerman (2006), Marcushi (2008), entre outros.

\section{Gêneros Textuais: Algumas Considerações}

A observação sistemática dos gêneros textuais vem desenvolvendo-se há vinte e cinco séculos, iniciando-se em Platão com a tradição poética, ligada aos gêneros literários, consolidando-se em Aristóteles com a tradição retórica, passando pela idade média, renascimento, modernidade, até o início do século XX.

Brandão (2003, p. 19) explicita que o tratamento dos gêneros textuais: 
contemporâneas em poética e semiótica literária e às teorias linguísticas atuais”. (BRANDÃO, 2003, p. 19)

Na contemporaneidade, a expressão gênero tem uma nova perspectiva, diferente da aristotélica, onde não se relaciona apenas com a literatura, tornando-se multidisciplinar. Dessa forma, os gêneros são uma forma de ação social, pois abrangem a língua nas mais diversas formas do cotidiano. (MARCUSHI, 2008).

O autor acrescenta ainda que:

Os gêneros devem ser vistos na relação com as práticas sociais, os aspectos cognitivos, os interesses, as relações de poder, as tecnologias, as atividades discursivas e no interior da cultura. Eles mudam, fundem-se, misturam-se para manter sua identidade funcional com inovação organizacional (MARCUSCHI, 2006, p. 25).

Para Bakthin (1988), a noção de gênero textual surge da necessidade de compreender à língua enquanto instrumento de interação social que, por sua vez, é historicamente determinada e constituinte do homem, da sociedade e do próprio sistema da língua.

Dentro desse sistema sociohistórico de comunicação, compreende-se que:

\begin{abstract}
As comunidades discursivas são redes sócio retóricas a fim de trabalharem em prol de conjuntos de objetivos comuns. Uma das características que os membros estabelecidos dessas comunidades discursivas possuem é a familiaridade com gêneros particulares que são usados no favorecimento desses conjuntos de objetivos. Consequentemente, os gêneros são propriedades das comunidades discursivas, ou seja, os gêneros pertencem às comunidades discursivas e não aos indivíduos, a outros tipos de agrupamento ou a comunidades de fala (Speech Comunity) mais amplas (SWALES, 1990, p. 9).
\end{abstract}

É justamente essa compreensão de esferas discursivas determinadas, bem como o pertencimento às comunidades discursivas que o ensino de língua portuguesa (BRASIL, 1998) visa promover uma reflexão sobre a práxis social, bem como dos próprios problemas sociais, por meio da compreensão dos usos e das formas linguísticas.

Dito de outra forma, o ensino na perspectiva dos gêneros textuais promove um espaço para construção crítica do conhecimento, ao superar o conhecimento de estruturas linguísticas como se estas, isoladamente, fossem capaz de tornar o sujeito proficiente em seus diversos usos. 
De acordo com Silva (2013, p. 51), esta concepção dialógica proposta pelo autor é decorrente da premissa básica de que "o signo para Bakhtin não é linguístico, mas ideológico, ou seja, é carregado de sentidos que dizem respeito a uma posição social, histórica e cultural”.

Ocorre a variação de teorias e interpretações em relação aos gêneros textuais; pois se trata de uma área interdisciplinar, fluída, com atenção especial para o funcionamento da língua, situada numa relação sócio histórica. Como afirma Miller (1984, APUD MARCUSHI, 2008, p. 151):

Desde que não concebamos os gêneros como modelos estanques nem como estruturas rígidas, mas como formas culturais e cognitivas de ação social, corporificadas na linguagem, somos levados a ver os gêneros como entidades dinâmicas.

Marcushi (2006) ressalta que, os gêneros são fenômenos históricos ligados à vida social e cultural dos sujeitos, surgem a partir das necessidades dos homens. Só interagimos verbalmente por meio de gêneros, estabelecemos uma comunicação por intermédio deles. A fala e a escrita das pessoas estão ligadas diretamente com os fatos sociais, ou seja, a organização social está vinculada com os gêneros, os textos se encaixam com as atividades sociais. A consciência e o conhecimento do ser humano não se constroem isoladamente, mas do processo de inter-relação com outros discursos e sujeitos.

Segundo Bazerman (2005), os textos estabelecem realidades para o leitor, pois contém afirmações, dessa forma, criam um fato social onde as pessoas acreditam na veracidade de algo, e a partir disso definem situações. A linguagem realiza ações sociais significativas, ou atos de fala, esses atos são realizados através dos gêneros. Esses atos de fala podem ser divididos em três níveis: o ato locucionário, aquilo que foi literalmente dito quando falamos ou escrevemos; o ato ilocucionário é o que pretende-se que o ouvinte entenda e por último o efeito perlocucionário, ou seja, o que as pessoas entendem que queiramos fazer, o efeito real da fala.

Quando falamos é possível que nossos ouvintes não compreendam e criem entendimentos divergentes, para coordenar melhor nossas ações de fala é preciso agir de modo típico. Se seguirmos padrões comunicativos que outras pessoas também utilizem, mais facilmente têm-se uma comunicação. De acordo com Bazerman (2005), as formas de comunicação reconhecíveis, realizadoras de determinados atos em determinadas circunstâncias, as características especiais de cada texto, chama-se de gêneros. 
Id on Line Revista Multidisciplinar e de Psicoloqia

Id on Line Multidisciplinary and Psychology Journal

Porém, os gêneros não são iguais para todas as pessoas, nem se limitam a traços textuais e elementos fixos. Os gêneros mudam constantemente conforme o tempo, cada pessoa tem uma forma de percepção dependendo da circunstância em qual o gênero se apresenta.

Uma compreensão mais aprofundada de gênero é reconhecermos a importância social na qual o gênero faz parte, facilitando e coordenando as atividades entre as pessoas, tipificando e dando forma ao texto, tornando prática as atividades sociais, compreendendo-o como um fenômeno de reconhecimento psicossocial (BAZERMAN, 2005).

A coleção de variados gêneros textuais que uma pessoa produz é um conjunto de gêneros, já um sistema de gêneros compreende diversos conjuntos de gêneros de forma organizada, interligando-se com o sistema de atividades de um grupo de pessoas, como também faz parte do sistema de atividades da sala de aula. Levando-se em consideração o sistema de atividade e sistema de gêneros, percebe-se que os textos não têm fins em si mesmos, e sim em ajudar as pessoas a "fazer" e "como fazer" determinadas ações.

O domínio discursivo classifica os textos de acordo com as suas instâncias comunicativas, podendo ser: discurso jurídico, discurso religioso entre outro. São práticas discursivas nas quais identifica-se os gêneros, não abrange um gênero, mas dá origem a diversos. Dessa forma, os tipos e os gêneros textuais não são diferentes, pelo contrário, estão integrados um com o outro, se completam, são partes que constituem o texto (MARCUSHI, 2008).

O gênero é um mecanismo que ajuda na regulamentação e na manutenção da sociedade, tornando-se um ambiente estruturado para a leitura e escrita, influenciando todos os aspectos da nossa vida. Em outras palavras: "gêneros emergem nos processos sociais em que as pessoas tentam compreender umas às outras suficientemente bem para coordenar atividades e compartilhar significados com vistas a seus propósitos práticos" (BAZERMAN, 2005, p. 31).

Os gêneros textuais estão ligados diretamente com os campos e aspectos sociais, cognitivos, históricos e culturais, direcionando e organizando a comunicação dos indivíduos. Para que o sujeito use-o de forma apropriada é necessário que o mesmo internalize os esquemas de utilização dos gêneros nas suas ações discursivas. Tem-se uma definição de gênero apresentada por Volochinov (1981 apud PEREIRA, 2014, p. 224): 
[...] o enunciado, considerado como uma unidade de comunicação e totalmente semântica, se constitui e se realiza exatamente em uma interação verbal determinada e gerada por dada relação de comunicação social. Dessa maneira, cada um dos tipos de comunicação social que citamos organiza, constrói e completa, de maneira específica, a forma gramatical e estilística do enunciado, assim como a estrutura do tipo que lhe dá origem: doravante, nós a designaremos sob o termo de gênero.

Tendo em vista o gênero como ferramenta de ensino-aprendizagem, Schneuwly (2004 apud PEREIRA, 2014) traz a concepção de gênero como "megainstrumento" que possibilita o desenvolvimento das ações discursivas.

Os gêneros trazem uma contribuição significativa e são importantes que sejam trabalhados em sala de aula, pois estão inseridos em uma dimensão sócio comunicativa. É através dos textos que interagimos, expressamos nossas opiniões e ideias, tecemos nossas críticas, ou seja, nos comunicamos por meio dos textos.

De acordo com Antunes (2005, p. 40) "O texto deve permear, assim, toda e qualquer atividade de sala de aula de língua (da mesma forma que ele permeia toda e qualquer atividade de nossa atuação social)".

As prescrições dos PCN's (BRASIL, 1998) tem sido recorrentes para o uso dos gêneros como referência no processo de ensino-aprendizagem. Diante disso, nas aulas de língua portuguesa tem-se trabalhado com os gêneros textuais, tornando as mesmas uma prática enriquecedora para os alunos, pois os gêneros são o eixo integrador na formação do educando, caracterizando-se como elemento essencial das ações linguísticas, fazendo-se presente em toda esfera social.

Como Antunes (2005) esclarece, para que o aluno desenvolva a sua competência linguística é imprescindível que o professor utilize os mais diversos tipos de gêneros textuais. O gênero redação, por exemplo, pode ser trabalhado em sala de aula visando à ampliação da competência argumentativa e crítica do aluno. Dito isto, no próximo capítulo teceremos algumas reflexões sobre o ensino e a prática da redação e a sua utilização nas aulas de língua portuguesa. 
Id on Line Revista Multidisciplinar e de Psicologia

Id on Line Multidisciplinary and Psychology Journal

\title{
O Gênero Redação: da Produção às duas Finalidades Contemporâneas
}

Partindo da concepção de gênero como canal discursivo, Marcushi (2000) afirma que os gêneros textuais não são instrumentos estanques, e ganham nova roupagem a medida que a interação humana apresenta essa necessidade. Essa posição em relação ao gênero ajuda a entender e situar o indivíduo como agente nessa construção.

Os gêneros textuais se transformam à medida que o ser humano adquire novas bases para darem suporte ao ato comunicativo, sendo assim tornam-se "novos gêneros textuais".

É de suma importância trabalhar os gêneros textuais em sala de aula nas mais variadas formas de contextos e suas funções na prática social, um trabalho a ser feito paralelo ao destaque que a estrutura do gênero recebe.

$\mathrm{Na}$ teoria, a proposta é bastante válida e parece suprir a necessidade de entendimento do uso dessas ferramentas textuais no processo comunicativo em sociedade, porém, na prática, o que ocorre é uma inversão onde o trabalho paralelo entre estrutura e função dá espaço apenas ao enfoque da estrutura do gênero. Relatos de experiência e a análise de materiais didáticos mostram como a dificuldade em dar espaço para a construção da função dos gêneros em sala de aula existe.

A interdisciplinaridade dos gêneros textuais, resulta na variedade de possibilidades do uso que o aluno faz no seu dia a dia e consiste no foco principal de que o aluno saia da posição de expectador para tornar-se agente consciente e crítico no uso da comunicação.

\begin{abstract}
Membros da comunidade compartilham os mesmos propósitos comunicativos. Esses propósitos são reconhecidos pelos membros mais experientes da comunidade discursiva original e constituem a razão do gênero. Esta racionalidade modela a estrutura esquemática do discurso e 29 influencia e restringe as escolhas de conteúdo e estilo. O propósito comunicativo, além de ser um critério privilegiado, também opera para sustentar o escopo de um gênero, mantendo-se enfocado estreitamente em determinada ação retórica compatível com o gênero. Além do propósito, os exemplares de um gênero exibem vários padrões de semelhança em termos de estrutura, estilo, conteúdo e audiência. Se num exemplar forem realizadas todas as expectativas sobre a caracterização de um determinado gênero, esse exemplar será visto como prototípico pela comunidade discursiva em que ele circula. Os nomes dos gêneros, herdados e produzidos pelas comunidades discursivas e importados por outras, constituem uma comunicação etnográfica valiosa, mas necessitam posteriormente de validação adicional (SWALES, 1990, p. 58).
\end{abstract}

O foco excessivo na estrutura dos gêneros compromete o sucesso da finalidade, pois para atingir esse objetivo o aluno precisa estar ciente que os gêneros são mutáveis, uma vez 
que eles atendem a necessidade dos falantes. $\mathrm{O}$ entendimento da estrutura é acessório pois permite ao aluno entender o seu meio social, uma vez que a estrutura é comum a todos.

Neste sentido, compreende-se que:

\begin{abstract}
a língua materna - sua composição vocabular e sua estrutura gramatical - não chega ao nosso conhecimento a partir de dicionários e gramáticas mas de enunciações concretas que nós mesmos ouvimos e nós mesmos reproduzimos na comunicação discursiva viva com as pessoas que nos rodeiam. Nós assimilamos as formas da língua somente nas formas das enunciações e justamente com essas formas. As formas da língua e as formas típicas dos enunciados, isto é, os gêneros do discurso, chegam à nossa experiência e à nossa consciência em conjunto e estreitamente vinculadas. Aprender a falar significa aprender a construir enunciados (BAKHTIN, 2003, p. 282-283).
\end{abstract}

Em conformidade com os Parâmetros Curriculares Nacionais (PCN's), no processo de ensino-aprendizagem espera-se que:

[...] o aluno amplie o domínio discursivo nas diversas situações comunicativas, sobretudo nas instâncias públicas de uso da linguagem, de modo a possibilitar sua inserção efetiva no mundo da escrita, ampliando suas possibilidades de participação social no exercício da cidadania (BRASIL, 1998, p. 32).

A partir dos gêneros é possível trabalhar diversas habilidades e estratégias na sala de aula, tendo em vista a sua função social.

O domínio do gênero redação é critério de avaliação nos exames nacionais, em sua maioria, também, ocupa o critério de desempate entre candidatos que disputam anualmente vagas nas universidades de todo país. Destacado como um medidor da qualidade do ensino no Brasil, a produção de redação exige cada vez mais que o aluno tenha domínio de habilidades linguísticas e uma opinião crítica a respeito de determinado tema. Nas propostas de redação alguns caminhos são apresentados aos alunos e o tema a ser trabalhado terá de ser desenvolvido respeitando formas e ferramentas que tragam à tona várias habilidades.

Dentre elas pode-se destacar a capacidade de dominar a norma culta da língua, a capacidade de elaborar argumentos coesos e concisos, a habilidade de apresentar soluções ou caminhos como forma de desdobramento do tema. Esses pontos estão em concordância com a proposta dada pelos PCN's, com o objetivo de que o aluno amplie o domínio discursivo. O modo como a produção de um gênero textual é enxergado no processo educativo contribui para definir que aspectos serão observados e contemplados pelo aluno cognitivamente. 
Id on Line Revista Multidisciplinar e de Psicologia

Id on Line Multidisciplinary and Psychology Journal

\title{
O Discurso do Professor à luz da Teoria Bakhtiniana
}

Na perspectiva Bakhtiniana, a língua/linguagem é caracteristicamente dialógica, ou seja, o indivíduo, como também os discursos que o constituem, são essenciais para a existência da língua. Bakhtin compreende a língua da seguinte forma:

\begin{abstract}
A verdadeira substância da língua não é um sistema abstrato de formas linguísticas nem pela enunciação monológica isolada, nem pelo ato psicofisiológico de sua produção, mas pelo fenômeno social da interação verbal, realizada através da enunciação ou das enunciações. A interação verbal constitui assim a realidade fundamental da língua. O diálogo, no sentido estrito do termo, não constitui, é claro, senão uma das formas, é verdade que das mais importantes, da interação verbal. Mas pode-se compreender a palavra 'diálogo' num sentido amplo, isto é, não apenas como a comunicação em voz alta, de pessoas colocadas face a face, mas toda comunicação verbal, de qualquer tipo que seja (BAKHTIN, 2006, p. 125).
\end{abstract}

Desde que entende-se a linguagem como uma forma de comunicação humana, assume-se uma concepção interacionista onde os falantes tornam-se sujeitos.

Os enunciados são as unidades concretas e reais de comunicação, ou seja, são a materialidade linguística; imutáveis e irrepetíveis, constituem um novo acontecimento da comunicação discursiva. O enunciado é composto por uma dimensão verbal, ou seja, a organização textual; bem como por uma dimensão social, o contexto social de interação. Desse modo, o discurso se materializa através dos enunciados, que são sempre construídos em determinados gêneros.

Afinal, por se tratar da redação um gênero escrito, partimos do pressuposto de que:

o enunciado constitui-se na interação entre interlocutores. Essa interação, no entanto, precisa ser ainda esclarecida: nao se trata sempre de um diálogo face a face, ou de um endereçamento explícito de minha fala ou escrita a alguém: quando falamos, sempre nos dirigimos a outro, ainda que não saibamos quem esse outro é; ao mesmo tempo, sempre estamos retomando o que outros já disseram. Esse é o princípio do dialogismo (SILVA, 2013, p. 52).

Nos PCN's a língua é referenciada como uma atividade sócio interacional em que o aluno precisa dispor de conhecimentos prévios para chegar a uma troca significativa com o receptor (BRASIL, 1998). É na forma de enunciar o discurso, que vemos o outro e, a partir 
desse outro, vamos construindo o mundo, um mundo de repletas interações, representado pelos sujeitos.

Para iniciar a análise, apresentaremos as perguntas aos professores, que foram aplicadas através de questionário, juntamente com as respostas dos mesmos, em seguida as nossas interpretações. Elaboramos um questionário constituído de 06 (seis) perguntas e entregamos à 04 (quatro) professores do ensino médio que lecionam em escolas particulares na cidade de Catolé do Rocha para que os mesmos respondessem as perguntas e em seguida fizemos o recolhimento para analisar as respectivas respostas. A maioria dos professores investigados estão em sala de aula há mais de 10 (dez) anos, dentre eles, somente o professor 3 possui mestrado, o restante possui somente graduação.

Vejamos, então, as perguntas com suas respectivas respostas:

\section{1 - Como você define o conceito de gêneros textuais?}

P1: São textos que possuem características comuns em sua estrutura, tipo de linguagem e conteúdo, sempre com um propósito específico de comunicação.

P2: Gêneros textuais podem ser definidos como diferentes textos escritos ou orais, que apresentam características diferentes, tendo em vista o objetivo da comunicação.

P3: É a maneira como a língua é empregada nos textos em suas mais variadas situações comunicativas. Tais formas podem assumir características formais ou informais e até se mesclarem em um dado texto.

P4: O conceito de gêneros textuais, está ligado a forma como moldamos nossas experiências e conhecimentos em forma de comunicação.

A primeira questão gira em torno do conceito de gêneros textuais e são perceptíveis os pontos de convergências entre as respostas dadas com a teoria desenvolvida por Bakhtin. Para Bakhtin:

Todos os diversos campos da atividade humana estão ligados ao uso da linguagem. Compreende-se perfeitamente que o caráter e as formas desse uso sejam tão multiformes quanto os campos da atividade humana, o que, é claro, não contradiz a unidade nacional de uma língua. O emprego da língua efetua-se em forma de enunciados (orais e escritos) concretos e únicos, proferidos pelos integrantes desse ou daquele campo da atividade humana (BAKTHIN, 2003: 261). 
Nas respostas dadas a primeira questão temos referências as diversas modalidades de uso dos gêneros, a característica modal que eles apresentam, tanto oral como escrito e o nível de formalidade que passam por eles, indo do mais informal até os gêneros mais complexos.

Marcushi (2008) ressalta que os gêneros são de difícil definição formal e caracterizam-se muito mais por suas funções comunicativas, cognitivas e institucionais do que por suas peculiaridades linguísticas e estruturais, isso não quer dizer que despreza-se a forma, pois em alguns casos é ela quem determina o gênero. Os gêneros são formas de ação social em qualquer situação comunicativa, surgem da necessidade sociocultural do ser humano, ou seja, são determinados de acordo com os objetivos dos falantes.

Trabalhar com os gêneros textuais em sala de aula é uma oportunidade para que o professor instigue o aluno a se relacionar com a língua nas suas mais diversas formas apresentadas em seu contexto de atuação. Enfim, o trabalho com os gêneros textuais vai de encontro com a proposta dos Parâmetros Curriculares Nacionais, na perspectiva de que o ensino da língua portuguesa seja desenvolvido a partir de conhecimentos adquiridos pelos alunos previamente.

\section{2 - Você conhece os documentos que falam sobre o ensino a partir de gêneros textuais?}

P1: Os Parâmetros Curriculares Nacionais abordam e orientam o trabalho com os gêneros.

P2: Sim, os Parâmetros Curriculares Nacionais são referência pois orientam o professor ao trabalhar com os gêneros textuais, trazendo uma reflexão sobre o ensino.

P3: Sim. Por exemplo, os PCN's, que oferecem aos profissionais de educação várias contribuições quanto ao ensino da língua portuguesa em sala de aula.

P4: Sim. Durante minha formação acadêmica a discussão sobre como os documentos oficiais (PCN's) trata o ensino a partir de gêneros foi frequente.

Na segunda questão é unânime a presença dos Parâmetros Curriculares Nacionais como documento referência quando se trata de ensino e de gênero. Como ponto de partida para discussões iniciais sobre as práticas de ensino e aprendizagem, os parâmetros deixam sua marca pelo caráter desafiador com o qual se apresentam desde a época de sua produção.

Os PCN's abordam uma perspectiva transformadora acerca da natureza da interação e da linguagem, as propostas encontradas nos documentos em sua maioria priorizam atividades 
Id on Line Revista Multidisciplinar e de Psicoloqia

Id on Line Multidisciplinary and Psychology Journal

que levem em consideração as escolhas que são feitas pelos falantes em suas respectivas produções, como por exemplo com quem eu falo, para quê e como. Bakhtin (1999, p. 118) ressalta que "o centro organizador de toda a enunciação, de toda a expressão não é interior, mas exterior: está situado no meio social que envolve o indivíduo".

Os Parâmetros Curriculares Nacionais apresentam bases teórico-metodológicas; são prescrições que norteiam o trabalho pedagógico e permitem com que o professor reflita sobre o ensino e a concepção do uso da língua dentro da sua real função, contribuindo de forma significativa, pois visa a ampliação das competências do aluno.

\section{3 - Como você trabalha os gêneros textuais?}

P1: Sim. Os diferentes gêneros textuais são abordados gradualmente desde o ensino fundamental.

P2: Costumo expor uma breve história do conceito de gênero e sua importância, em seguida apresento o gênero a ser estudado, sua interpretação, elementos e função.

P3: Não me prendo a uma categoria quanto aos gêneros textuais e o seu uso, pois não são compatíveis com uma mentalidade normativa, mas uma forma de uso é por meio de sequência didática.

P4: De forma contextualizada, buscando estabelecer ligação entre o material que eu apresento com as vivências de cada aluno.

A terceira questão acerca do trabalho com gêneros textuais divide opiniões no sentido de práticas metodológicas e de detalhamento. Para P1, nota-se uma confiança quanto a familiarização por parte dos alunos com gêneros uma vez que eles são trabalhados desde as séries iniciais. O seu trabalho então seria o de continuar com esse percurso.

$\mathrm{Na}$ P2 temos um trabalho mais explícito construído em cima de etapas, o professor leva o aluno desde a parte conceitual até o momento analítico passando por cada etapa de conhecimento separadamente.

O P3 desenvolve um trabalho também em etapas, mas baseado em sequências didáticas. Sequências didáticas são atividades desenvolvidas separadamente que possuem relação umas com as outras e que tem por objetivo o conceito principal dessas atividades. Esse modo de trabalho tem probabilidades de bons resultados por abrir oportunidades em sala 
para interação entre os envolvidos, uma vez que serão trabalhadas mais de uma atividade acerca do mesmo gênero.

Com base nos Parâmetros Curriculares Nacionais, o ensino de Língua Portuguesa deve centralizar-se em três grandes variáveis:

\footnotetext{
O primeiro elemento dessa tríade - o aluno - é o sujeito da ação de aprender, aquele que age com e sobre o objeto de conhecimento. O segundo elemento o objeto de conhecimento - são os conhecimentos discursivo -textuais e linguísticos implicados nas práticas sociais de linguagem. O terceiro elemento da tríade é a prática educacional do professor e da escola que organiza a mediação entre sujeito e objeto do conhecimento (BRASIL1998, p. 22).
}

Os PCN's defendem o uso da língua como interação, no intuito de fazer com que o aluno entenda que os textos assumem uma função comunicativa. Dessa forma, percebe-se que o processo de ensino-aprendizagem defendido pelos PCN's está relacionado com a interação entre aluno, conhecimento e prática educacional do docente.

\section{4 - Qual a importância da utilização dos gêneros textuais?}

P1: Os gêneros textuais fazem parte do nosso cotidiano, por isso é importante não só conhecê-los, mas também aplicá-los com eficiência.

P2: São importantes no processo de ensino-aprendizagem da língua portuguesa, uma vez que colaboram no desenvolvimento da linguagem e contribuem ao acesso da língua em funcionamento.

P3: A utilização dos gêneros possibilita, em muito, por exemplo, a ocorrência de um caráter educacional diferenciado, uma vez que os falantes se tornam sujeitos e, como se sabe, é atribuição da escola contribuir com a formação de tais sujeitos, sendo que a utilização dos gêneros textuais se constitui em uma das formas de ensino para conquistar uma melhor visão de mundo, por meio da língua.

P4: É importante para despertar no aluno a noção de que existem várias formas nas quais o mesmo pode interagir com o mundo.

Os depoimentos obtidos na quarta questão trazem de volta a visão sócio histórica utilizada por Bakhtin sobre a natureza da interação. Fica claro que para os 4 entrevistados há de se levar em consideração o contexto de produção que o aluno se encontra. Esse contexto é 
Id on Line Revista Multidisciplinar e de Psicoloqia

Id on Line Multidisciplinary and Psychology Journal

construído pelo nível de familiarização dos alunos com os gêneros, o local e época onde os mesmos se encontram e a finalidade da construção crítica através desse trabalho.

Os PCN's quando foram lançados, traçaram um objetivo comum aos conteúdos a serem trabalhados em meio ao contexto de evolução tecnológica e social que acontecia no Brasil no final dos anos 90. Esse objetivo foi caracterizado pelo desenvolvimento do engajamento discursivo no aluno. Discutir gêneros textuais está intimamente conectado a essa questão, uma vez que os gêneros textuais são os moldes nos quais o aluno organiza suas experiências e conhecimentos e transmite-os por meio da interação social. Levando em consideração esses aspectos, fica claro a importância de trabalhar em sala de aula as mais variadas formas de contextos e suas funções na prática social, um trabalho a ser feito paralelo ao destaque que a estrutura do gênero recebe. (BRASIL, 1998)

Para os professores investigados em concordância com os PCN's de língua Portuguesa, os gêneros textuais são instrumentos significativos para o processo de ensinoaprendizagem, pois permitem e facilitam o desenvolvimento das habilidades dos alunos, bem como contribuem para uma transformação no olhar sobre o funcionamento e o uso social da língua.

Os gêneros são o eixo integrador na formação do educando, caracterizando-se como elemento essencial das ações linguísticas, fazendo-se presente em toda esfera social. (BRASIL, 1998)

\section{5 - Como é desenvolvido o trabalho com o gênero redação?}

P1: Geralmente, a ênfase é dada ao texto dissertativo argumentativo, com vistas aos processos seletivos; mas os demais também são estudados.

P2: O trabalho é realizado com base nos conhecimentos prévios e interpretativos dos alunos relacionando o tipo de texto, sua estrutura e tema abordado.

P3: Apesar de trabalhar no ensino médio, cujo foco se volta para redação do ENEM, não me prendo somente a esta e sempre busco construir estratégias de forma que a produção textual se torne um convite contínuo para o aluno. Acho recomendável que o texto seja visto como um fenômeno sócio-cognitivo-interacional e deve ser tratado sempre no contexto de interesse do estudante, por meio de atividades práticas. 
P4: Primeiro com análises de redações que levo para sala de aula e posteriormente a produção delas.

Pela forma como a redação é entendida atualmente pelos diversos veículos que oferecem o trabalho com o gênero (que não são somente as escolas, já que a influência de cursos especializados e preparatórios para exames define o tom por exemplo do foco na argumentação), temos uma divisão na forma de ensino por parte dos professores.

Para P1 a redação-dissertação argumentativa marca seu trabalho embora não tome o espaço total, dando oportunidade de trabalhar com diferentes gêneros. Para P2 e P3 é mais relevante que o trabalho com redação esteja relacionado com o interesse dos alunos, esse interesse é usado como ferramenta para ativar os conhecimentos prévios e estimular o desenvolvimento dos temas de forma mais natural e contínua, uma vez que as chances dos alunos apresentarem material nessas produções é maior em casos onde há um interesse em comum com o tema. Para P4 a atividade leva em consideração a reprodução, que se assemelha com a visão Bakhtiniana de aquisição da linguagem. Para Bakhtin (2006) adquirimos a linguagem baseados em enunciados e estruturas vistas sendo reproduzidas por outras pessoas.

O ensino na perspectiva dos gêneros textuais promove um espaço para construção crítica do conhecimento, ao superar o conhecimento de estruturas linguísticas como se estas, isoladamente, fossem capaz de tornar o sujeito proficiente em seus diversos usos.

\section{6 - Quais competências são avaliadas na redação?}

P1: Coesão, coerência, domínio da ortografia e clareza textual.

P2: As competências são: o domínio da norma padrão da língua escrita, capacidade de organizar e relacionar informações, construção de argumentos e elaboração de intervenção ao problema exposto.

P3: Não me preocupo em avaliar somente as questões gramaticais, busco auxiliar o aluno, entrando um pouco no seu mundo, auxiliando ao redator a expressar esse mundo por escrito. Tento levá-lo a pensar por escrito. Obviamente também não posso desconsiderar as competências usadas para correção da produção textual do ENEM, pelo fato de trabalhar no ensino médio.

P4: O que mais observo é a capacidade de os alunos utilizarem a língua (gramática) e de transmitir suas ideias com coerência e objetividade. 
$\mathrm{Na}$ última questão o modelo coesão-coerência predomina na busca por critérios de uma boa produção aliados ao léxico da língua. Os professores não devem deter-se apenas as questões gramaticais, mas sim como o aluno entende o funcionamento da língua. Antunes (2002) esclarece como deve ser a prática pedagógica:

\begin{abstract}
a apreensão dos "fatos lingüísticos-comunicativos" e não o estudo de "fatos gramaticais", difusos, virtuais, descontextualizados, objetivados por determinações de um "programa" previamente fixado e ordenado desde as propriedades imanentes do sistema lingüístico; b) a apreensão de estratégias e procedimentos para promover-se a adequação e eficácia dos textos, ou o ensino da língua com o objetivo explícito e determinado de ampliar-se a competência dos sujeitos para produzirem e compreenderem textos (orais e escritos) adequados e relevantes; c) a consideração de como esses procedimentos e essas estratégias refletem-se na superfície do texto, pelo que não se pode, inconseqüentemente, empregar quaisquer palavras ou se adotar qualquer sequiência textual; d) a correlação entre as operações de textualização e os aspectos pragmáticos da situação em que se realiza a atividade verbal; e) a ampliação de perspectivas na compreensão do fenômeno lingüístico, superandose, assim, os parâmetros demasiados estreitos e simplistas do "certo" e do "errado", como indicativos da boa realização lingüística (ANTUNES, 2002, p. $71)$.
\end{abstract}

Visando a melhoria do ensino da língua, o professor como agente transformador, deve considerar como prioridade que o aluno saiba organizar as ideias, interagir com o outro utilizando a língua, oral ou escrita, dispensando a rigidez de definições e regras, impedindo na maioria das vezes que o aluno compreenda os fatos linguísticos.

Em conformidade com Antunes (2002) e com os PCN's (1998), para o P3 é importante além desses aspectos gramaticais, considerar a visão de mundo do aluno na produção uma vez que o mesmo é levado a "pensar por escrito". Dessa forma, percebemos um profissional empenhado em privilegiar o uso da língua em diferentes situações, contribuindo para a formação de um leitor-escritor mais criativo, crítico e consciente.

\title{
Considerações Finais
}

As discussões elencadas neste trabalho sempre voltadas para natureza interacional da língua e o caráter construtivo-social que o trabalho com gêneros possui nos levam a um ponto comum sobre como o trabalho com a redação nos oferece essa finalidade quando feito contextualizadamente. 
Id on Line Revista Multidisciplinar e de Psicoloqia

Id on Line Multidisciplinary and Psychology Journal

Acerca do ensino baseado em explorar nomenclaturas gramaticais e exemplos isolados de contexto, Antunes (2002) defende uma prática que exija mais nesse aspecto que podemos aplicar ao ensino e produção de Redação. O modo de trabalho de alguns professores está ligado a ideia clássica de que a Redação tem uma fórmula pronta, atendendo a estrutura necessária, uma pitada de coesão e coerência e muita norma culta como marca de um texto polido. Essa prática deixa de lado o que é mais importante nesse momento de aprendizagem: a contribuição genuína do aluno.

Com essa conclusão não estamos dizendo que deve-se abandonar conceitos ligados a clássica normativa nem ignorar a estrutura já firmada para o gênero, mas que essa prática deve ir além desses tópicos e vencer a superficialidade. Principalmente por que explorar a prática de produção de texto requer o trabalho com diversos tipos de conhecimentos, domínios e garantir que além de saber estruturar um texto ou usar a norma padrão da língua, o aluno também saberá a importância de sua própria história e do seu papel nesse momento.

Trazer as vivências do aluno e transformar o modo como ele vê o mundo em argumentos e produções críticas que garantam sua participação efetiva na sociedade exige uma busca maior pelo aperfeiçoamento desse aluno que fuja do engessamento estrutural. É também levá-lo a entender como utilizar a introdução, o desenvolvimento e a conclusão do texto como instrumento para se engajar e engajar os outros no seu discurso.

Se a prioridade é dada as regras ou algum modo pronto de chegar ao resultado final da produção, o aluno terá dificuldade de se aproximar da ideia que os gêneros existem para cumprir uma necessidade linguística e que para isso nós os moldamos a medida que essa necessidade se apresenta. Esse sendo um ponto importante para caracterizar o percurso que o aluno faz até a concepção de seu pensamento crítico. Não há sentido bater na tecla que o aluno precisar conhecer as mais variadas formas de comunicação para estar inserido num mundo cada vez mais globalizado e não oferecer a ele oportunidades de trabalhar essas variações. No grupo de atividades que podemos elencar para essa finalidade as opções são tantas quantas as diferentes inteligências que encontramos em sala de aula.

Percebe-se como tem sido desafiadora a construção do saber com bases teóricas e metodológicas que beneficiem a proposta de ensino-aprendizagem da sociedade dinâmica e diversificada na qual os sujeitos estão inseridos. (BRASIL, 1998). O fato de o professor ter o interesse de aproximar o estudo da língua desse ideal de competências para a cidadania, já é 
Id on Line Revista Multidisciplinar e de Psicoloqia

Id on Line Multidisciplinary and Psychology Journal

um passo significativo, pois, dessa forma o professor adotará uma prática pedagógica capaz de oferecer resultados mais positivos e gratificantes. (ANTUNES, 2003)

É uma proposta teórica que irá encontrar obstáculos por motivos de estrutura e organização educacional como se apresenta no nosso país, porém a natureza interacional da língua deve ser priorizada e o professor como mediador tem um papel relevante diante da prática de ensino. Onde essa proposta puder ser trabalhada contribuirá de forma satisfatória, pois o aluno terá a oportunidade de saber que tem papel e uma função ilimitada na sociedade em que vive.

\section{Referências}

ANTUNES, Maria Irandé Costa Morais. Língua, gêneros textuais e ensino: considerações teóricas e implicações pedagógicas. Perspectiva: Revista do Centro de Ciências da Educação. Universidade Federal de Santa Catarina. Centro de Ciências da Educação - v. 20, n 1. Florianópolis, 2002. 65-75.

. Aula de português: encontro \& interação. São Paulo: Parábola Editorial, 2003.

. Lutar com palavras: coesão e coerência. São Paulo: Parábola Editorial, 2005.

BAKHTIN, M. [VOLOCHÍNOV, V.N.] (1986). Marxismo e Filosofia da Linguagem: problemas fundamentais do método sociológico na ciência da linguagem, $3^{\mathrm{a}}$ edição. Traduzido por M. Lahud \& C. H. D. Chagas Cruz. São Paulo, SP: Hucitec. (Trabalho original publicado 1929).

BAKHTIN, M. Estética da criação verbal. São Paulo: Martins Fontes, 2003.

Marxismo e filosofia da linguagem. São Paulo: Hucitec. 1999

A Estética da Criação Verbal. Trad. Ma Ermantina Galvão G. Pereira. São Paulo: Martins Fontes, 2000.

BAKHTIN, M. (VOLOCHINOV). Marxismo e Filosofia da Linguagem. Trad. De M. Lahud e Y. F. Vieira. 12a ed. São Paulo: Hucitec, 2006.

BAZERMAN, C. Gêneros textuais, tipificação e interação. Org.: Â. Paiva Dionísio e J. C. Hoffnagel. São Paulo: Cortez, 2005.

Cortez, 2006.

Gênero, Agência e Escrita. Org.: A P. Dionísio \& J. C. Hoffnagel. São Paulo: 
BRASIL. Parâmetros curriculares nacionais: Ensino Médio: Linguagens, códigos e suas tecnologias/Ministério da Educação. - Brasília: Ministério da Educação/Secretaria de Educação Média e Tecnologias, 1998.

CHOMSKY, N. Aspectos da teoria da sintaxe. Trad.: J. A. Meireles e E. P. Raposo. Coimbra: Armênio Amado Editora, 1965.

MARCUSCHI, Luiz Antonio. Gêneros textuais: configuração, dinamicidade e circulação. In: KARWOSKI, Acir Mário; GAYDECZKA, Beatriz \& BRITO Karim Siebeneicher (Orgs.) Gêneros textuais: reflexões e ensino. 2a ed. Rio de Janeiro: Lucerna, 2006.

Gêneros textuais no ensino de língua. In: Produção textual, análise de gêneros e compreensão. São Paulo: Parábola, 2008.

PEREIRA, Regina Celi Mendes (Org.) Ateliê de gêneros acadêmicos. João Pessoa: Ideia, 2014.

SAUSSURE, F. de. Curso de linguística geral. São Paulo: Cultrix, 1916.

SILVA, Camilo Rosa (Org.) Ensino de português: demandas teóricas e práticas. João Pessoa: Ideia, 2013.

SWALES, J. M. Genre Analysis: english in Academic and Research Settings. Cambridge, 1990.

Como citar este artigo (Formato ABNT):

MAIA, F.I.A.; SILVA, H.M.L.; UCHÔA, S.A.O.; CABRAL, S.A.A.O.; ALENCAR, M.C.B.; ROBERTO, S.B.A.; MACIEL, J.A.S. Ensino de Língua Portuguesa e o Gênero Redação: Uma análise do discurso do professor. Id on Line Revista Multidisciplinar e de Psicologia, Out-Nov. de 2016, vol.10, n.31, Supl 3, p. 120-140. ISSN 1981-1179.

Recebido: 18/10/2016

Aceito: 26/10/2016 